\title{
Development and Characterization of Ceramic Matrix Composite (CMC) from Nigerian Kankara Kaolin and Gray Cast Iron Filling
}

\author{
Ruth Matba Gadzama1 ${ }^{*}$, U. A. A. Sullayman², A. M. Ahuwan², D. S. Yawaz ${ }^{3}$ \\ ${ }^{1}$ Department of Industrial Design, Moddibo Adama University of Technology, Adamawa, Yola, Adamawa State, \\ Nigeria \\ ${ }^{2}$ Department of Industrial Design, Ahmadu Bello University, Zaria, Kaduna State, Nigeria \\ ${ }^{3}$ Department of Mechanical Engineering, Ahmadu Bello University, Zaria, Kaduna State, Nigeria \\ Email:"gdmataba@gmail.com
}

Received 22 December 2015; accepted 26 January 2016; published 29 January 2016

Copyright @ 2016 by authors and Scientific Research Publishing Inc.

This work is licensed under the Creative Commons Attribution International License (CC BY).

http://creativecommons.org/licenses/by/4.0/

(c) (i) Open Access

\section{Abstract}

This study developed a ceramic composite material (CMC) for use as a refractory material from "Kankara" clay (kaolin) as a matrix material mixed with gray cast iron (GCI) as reinforcement. The CMCs were prepared by varying the percentage by weight of the gray cast iron using 5, 10, 15, 20, $25,30,35,40$ and $45 \mathrm{wt} \%$. Tests were conducted on the developed CMC, using standard test techniques, to determine physical and the mechanical properties of the produced composites. The results for mechanical properties showed improvement in the hardness value from $47 \%$ at $5 \%$ GCI content to $94 \%$ at $45 \% \mathrm{GCI}$ content; the compressive strength improved from $3.11 \%$ at $5 \% \mathrm{GCI}$ to a peak of $7.15 \%$ at $25 \% \mathrm{GCI}$ and then descended down to $3.74 \%$ at $45 \%$ GCI content while the ultimate tensile strength improved from $0.75 \%$ at $5 \%$ GCI to a peak of $1.87 \%$ at $25 \%$ GCI down to $1.34 \%$ at $\mathbf{4 5 \%}$ GCI content. Equally, there is an increase in bulk density from $1.74 \%$ for $5 \%$ GCI content to $2.09 \%$ for $45 \% \mathrm{GCI}$ contentment. The linear shrinkage reduced from $11.57 \%$ to $1.15 \%$; water absorption also reduced from $33.68 \%$ to $15.20 \%$; apparent porosity too reduced from $42.2 \%$ to $16.02 \%$. However, cold crushing strength initially increased with increase in GCI content from 3.89 to a peak of $13.32 \mathrm{~V}$ for $25 \% \mathrm{GCI}$ content and progressively dropped to a value of $5.25 \mathrm{~V}$ at $45 \%$ GCI content. All the values obtained from the blends are within the recommended values for kiln shelves. However, the CMC developed on $25 \%$ GCI content showed the best combination of both mechanical and physical properties required of a good material for the production of kiln shelves.

\footnotetext{
${ }^{*}$ Corresponding author.
}

How to cite this paper: Gadzama, R.M., Sullayman, U.A.A., Ahuwan, A.M. and Yawaz, D.S. (2016) Development and Characterization of Ceramic Matrix Composite (CMC) from Nigerian Kankara Kaolin and Gray Cast Iron Filling. Journal of Minerals and Materials Characterization and Engineering, 4, 103-118. http://dx.doi.org/10.4236/jmmce.2016.41010 


\section{Keywords}

\section{Characterization, Kankara Clay, Gray Cast Iron, Composite and Refractory}

\section{Introduction}

With the rapid development of ceramic industry in Nigeria, the high demand for props, shelves, and shelf bars (used in day to day ceramics manufacture), makes the development of local materials for the production of kiln furniture very imperative. Ceramic matrix composites (CMC) as the name implies combine reinforcing ceramic or metal phases in a ceramic matrix to create materials with new and superior properties [1]. CMCs have been and are being developed to overcome the hitherto intensive brittleness and lack of reliability of monolithic ceramics thus making them suitable for use as structural parts in varying applications and environments like rockets and engines construction; gas turbines for power plants; heat shields for space vehicles, fusion reactor first walls, aircraft brakes, heat treatment for nacres, etc. According to [1] the ceramic matrix composites possess additional qualities like high mechanical strength, at high temperatures, high toughness, light stiffness and high corrosion resistance at high temperatures.

It was reported by [2] that most of the pottery establishments in Nigeria depended on foreign countries for the supply of kiln shelves and other kiln furniture. As a result of this, scarce foreign reserves are expended in purchasing these items. Apart, there is high risk of product loss/damage in transit due to the degree of fragility of ceramic wares. In addition, the time spent in bringing the foreign products contribute to the ineffectiveness of putting the equipment to use to when required.

The essence of this work is to develop ceramic composites using Kankara clay (kaolin) as a matrix and grey iron powder as a reinforcement, which can be used for the production of kiln furniture that can withstand high temperature.

\section{Materials \& Methods}

Kankara kaolin used as the aluminosilicate in the matrix was excavated from a clay pit located in Kankara village of Katsina state. Gray cast iron powder was purchased from National Metallurgical Development centre, Jos. Other materials used included water for the mixture. The equipment used in this research work include: Soil Test Compression Machine, Universal Testing Machine, Density Bottles, Furnace, Charpy Impact Machine, Shore A Durometer hardness testing machine, Vernier Caliper. Digital balance and Thermometer.

\subsection{Preparation of Samples}

After collecting the kaolin from its deposit in Kankara, Katsina State of Nigeria and grey iron powder from National Metallurgical Development Centre, Jos. The kaolin was beneficiated by wet screening it through a $75 \mu \mathrm{m}$ mesh [3]-[5]. Other processing routes that followed include calcining, crushing, grinding, sieving and mixing of the refractory batch. The grey cast iron was also grated into the required grain sizes of $75 \mu \mathrm{m}$ mesh [3] (see Figure 1 and Figure 2) through the process of powder metallurgy. Then the grey cast iron and kankara clay in powder form were weighed out in varied proportions and then poured into a clean basin and mixed thoroughly. Then a measured quantity of water was added followed with continuous mixing to paste form. After mixing, the composite blend was casted under pressure into wooden moulds of $100 \times 100 \mathrm{~mm}$ dimension. Casted samples were then air dried (Figure 3 and Figure 4) in fourteen days and sun dried for two days before firing. The composite samples were fired to temperature of $1280^{\circ} \mathrm{C}$ for 5 hours. Then they were allowed to cool in the furnace. This was done to cure the composite materials at the said temperature. The composition of blends is shown Table 1.

\subsection{Method of Characterization}

The type of density most commonly determined for a ceramic object is the bulk density, which is the weight divided by the bulk volume. The density and porosity of the samples were determined using Archimedes' technique (ASTM C 20-87). This method involves the determination of the following properties of sintered products: 


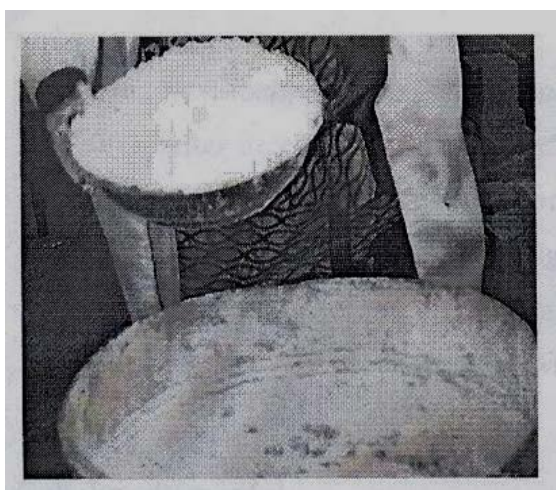

Figure 1. Mixing of the raw material according to proportion gray cast iron and kankara clay (kaolin).

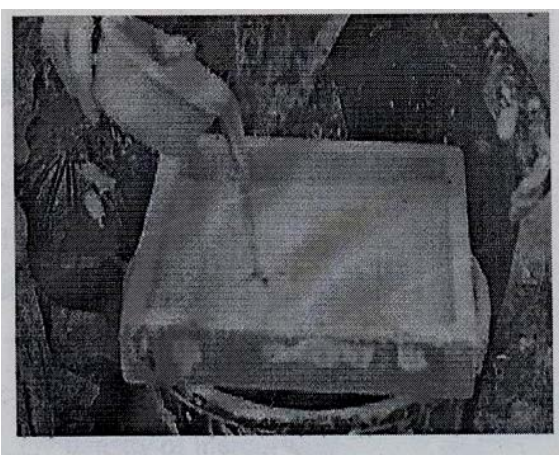

Figure 2. Sieving of raw materials kankara clay \& gray cast iron.

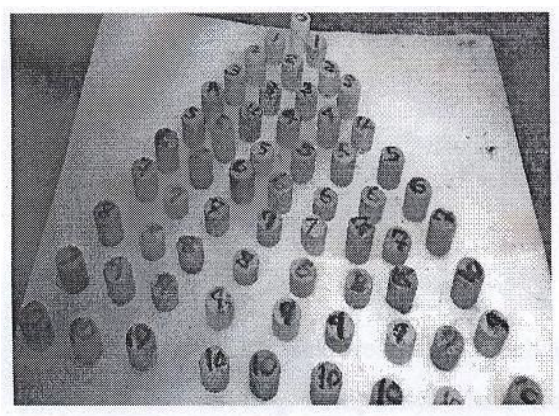

Figure 3. Tests samples from the mixture of kankara gray cast iron this done to get the bes coposition to be use to form the kiln furniture.

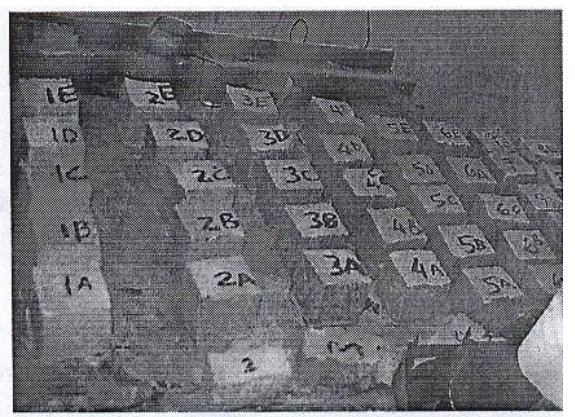

Figure 4. Tests samples from the mixture of kankara clay (kaolin) and clay (kaolin) and gray cast iron. The above samples will show the best number which is to be used. 
Table 1. Composition blends of composite materials produced.

\begin{tabular}{ccc}
\hline S/N & Kaolin Powder (\%) & Gray cast iron powder (\%) \\
\hline 1 & 100 & 0 \\
2 & 95 & 5 \\
3 & 90 & 10 \\
4 & 85 & 20 \\
5 & 80 & 25 \\
6 & 75 & 30 \\
7 & 70 & 35 \\
9 & 65 & 40 \\
10 & 60 & 45 \\
\hline
\end{tabular}

apparent porosity, water absorption, and bulk density. The dry weights of sintered samples were recorded as the initial step of this method. Each test specimen was boiled for 2 hours in water. After boiling, each specimen was cooled to room temperature while still completely covered with water, and immersed in water for a minimum of 12 hours before weighing. The suspended weight in water of each specimen was measured on the balance with Archimedes' apparatus (PrecisaXP22OA). After determining the suspended weight, the specimen was wiped with a wet sponge to remove drops of water from the surface. The damp specimen was then weighed to determine its saturated weight. The density and other properties were determined based on these three weights. In this case dry weight was noted as $(D)$. Suspended weight was noted as $(S)$ while saturated weight was $(W)$. Volume of specimen $=W_{2} / d$ where $d=$ density of mercury.

$$
\text { Bulk density }-\frac{w_{1}}{w_{2}} d
$$

The apparent porosity is then calculated as:

$$
P_{(a p p)}-\frac{W-D}{W-S} \times 100(\%)
$$

where,

$W-D=$ actual volume of open pores of the specimen.

$W-S=$ External volume of the specimen.

The micro structural features of as-received powders (Kankara clay and grey iron powder), as well as those of the developed composites obtained from them were investigated using a scanning electron microscope (model SEM-Philips XL-30 SFEG). SEM tests, which included elemental analysis of as-received powders and the ceramic composite kiln shelves and prop samples using SEM-Energy Disperse Spectrometry (SEM-EDS), were carried out in Johannesburg South Africa. The morphological characterization of the grains and pores were evaluated on polished surfaces as shown in Figures 5-14.

To determine the linear shrinkage, the green samples after press moulding, were allowed to dry until they can be removed conveniently from the dry mold and their dimensions were taken in that condition. They were then fired in the furnace to a temperature of $1600^{\circ} \mathrm{C}$ upon cooling from which the new dimensions were measured, using the vernier caliper, and recorded. The linear shrinkages were then calculated as a percentage of the original green length as shown below:

$$
\text { \%of fired shrinkages }=\frac{L_{B}-L_{D}}{L_{B}} \times 100(\%)
$$

where, $L_{B}=$ Dimension of green samples, $L_{D}=$ Dimension of fired samples.

The cold crushing strength of the composite was determined using an asbestos board of about 5 mm thickness 


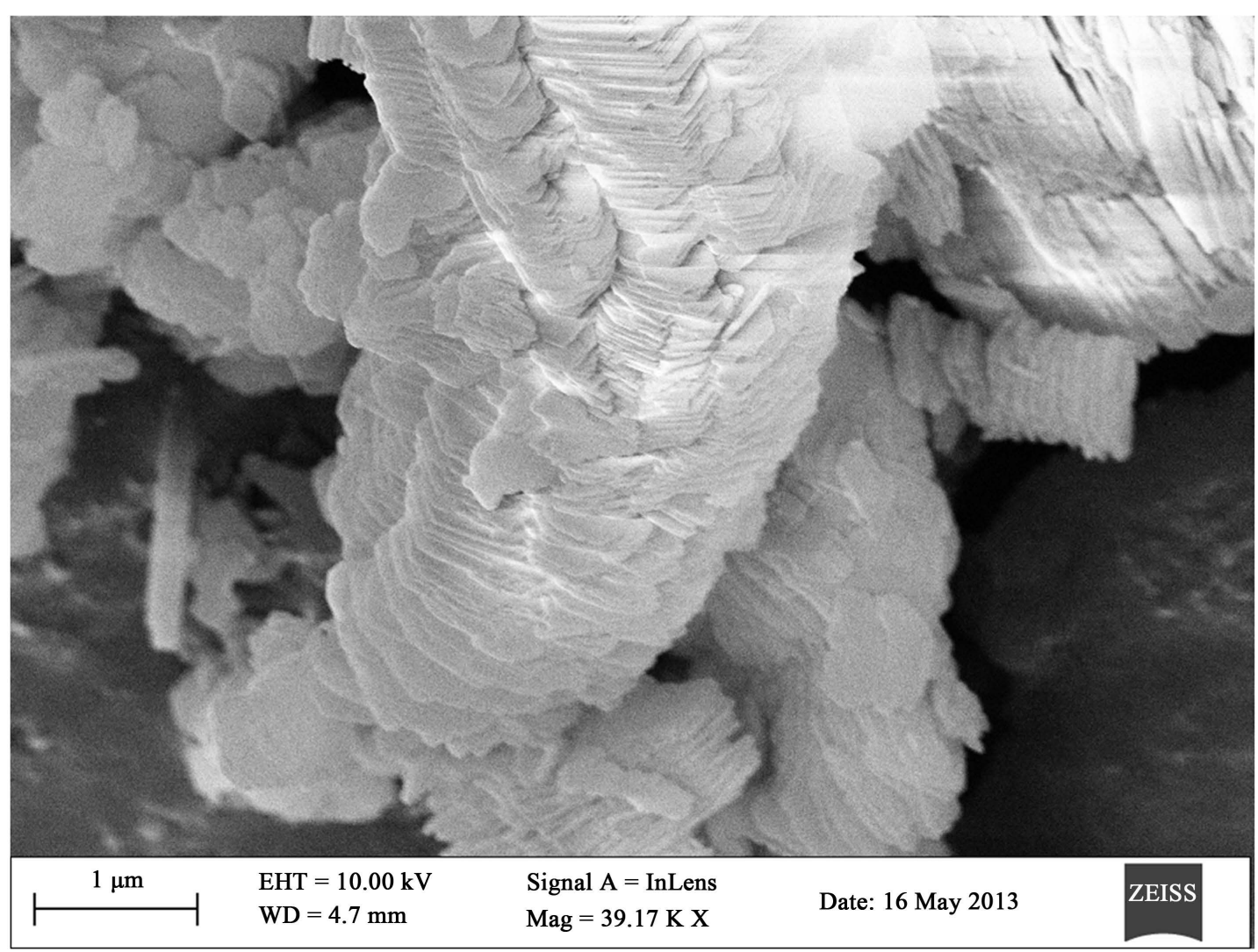

Figure 5. Micrograph of sample with $0 \%$ grey cast iron.

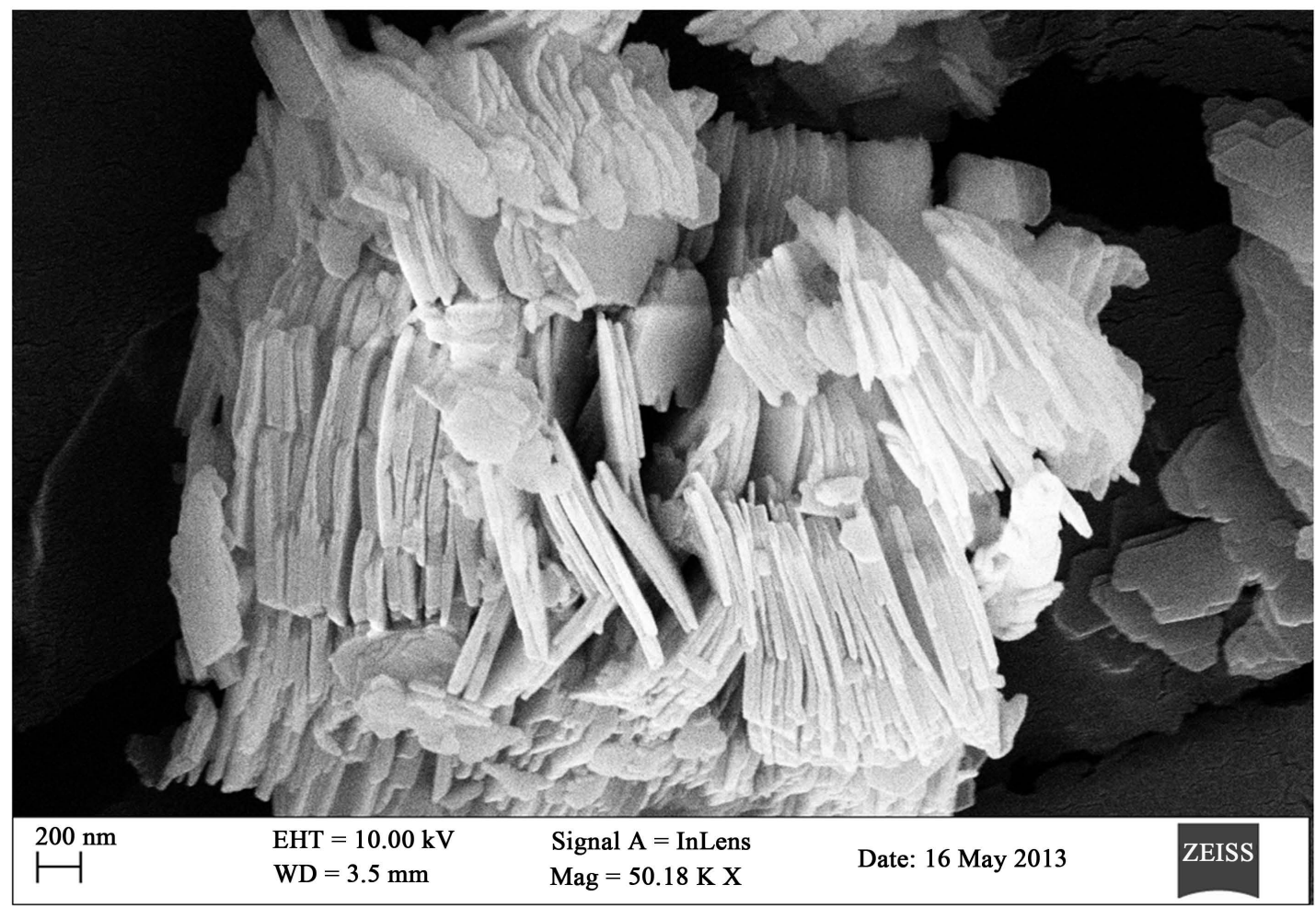

Figure 6. Micrograph of sample with 5\% grey cast iron. 


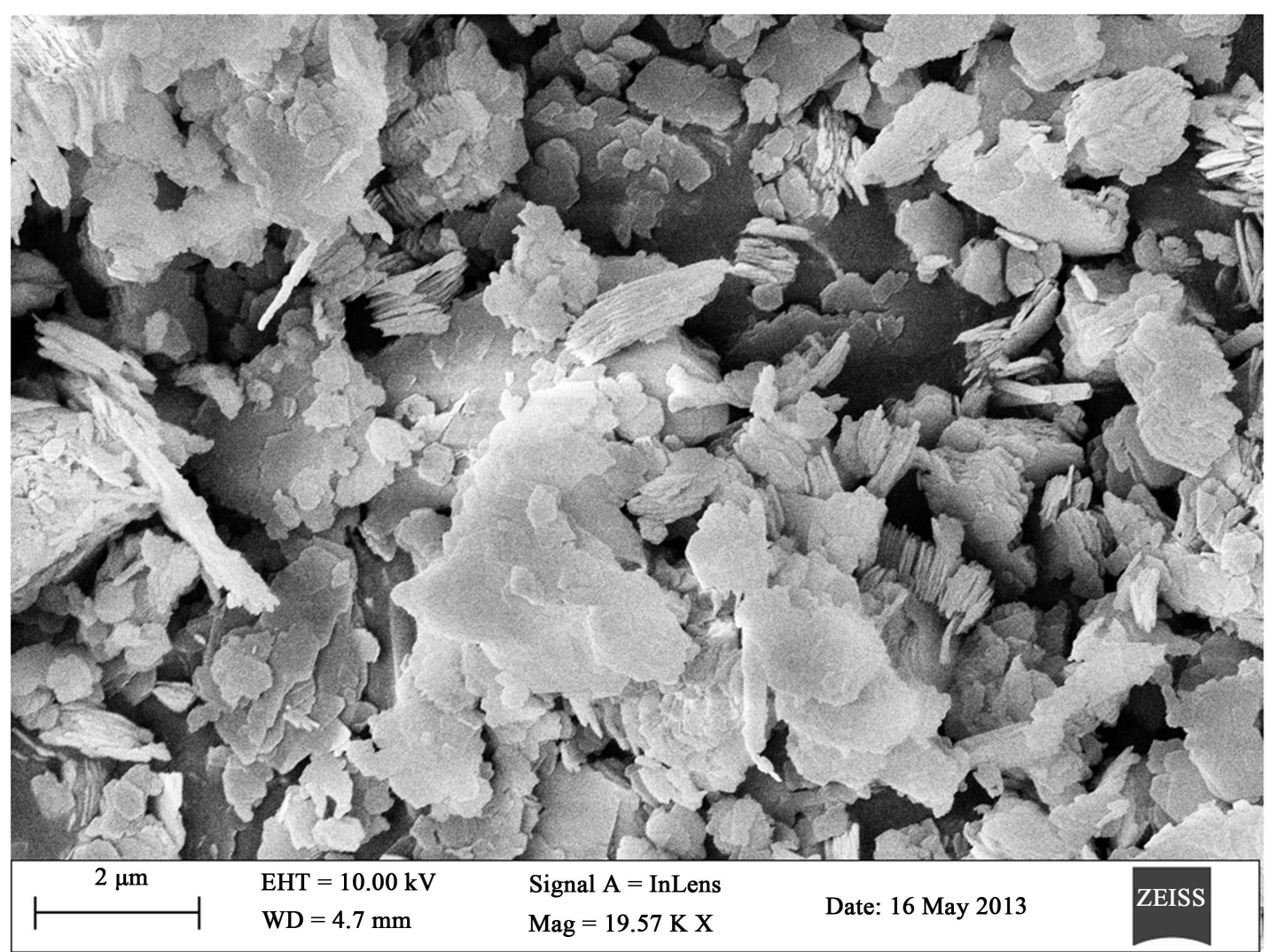

Figure 7 . Micrograph of sample with $10 \%$ grey cast iron.

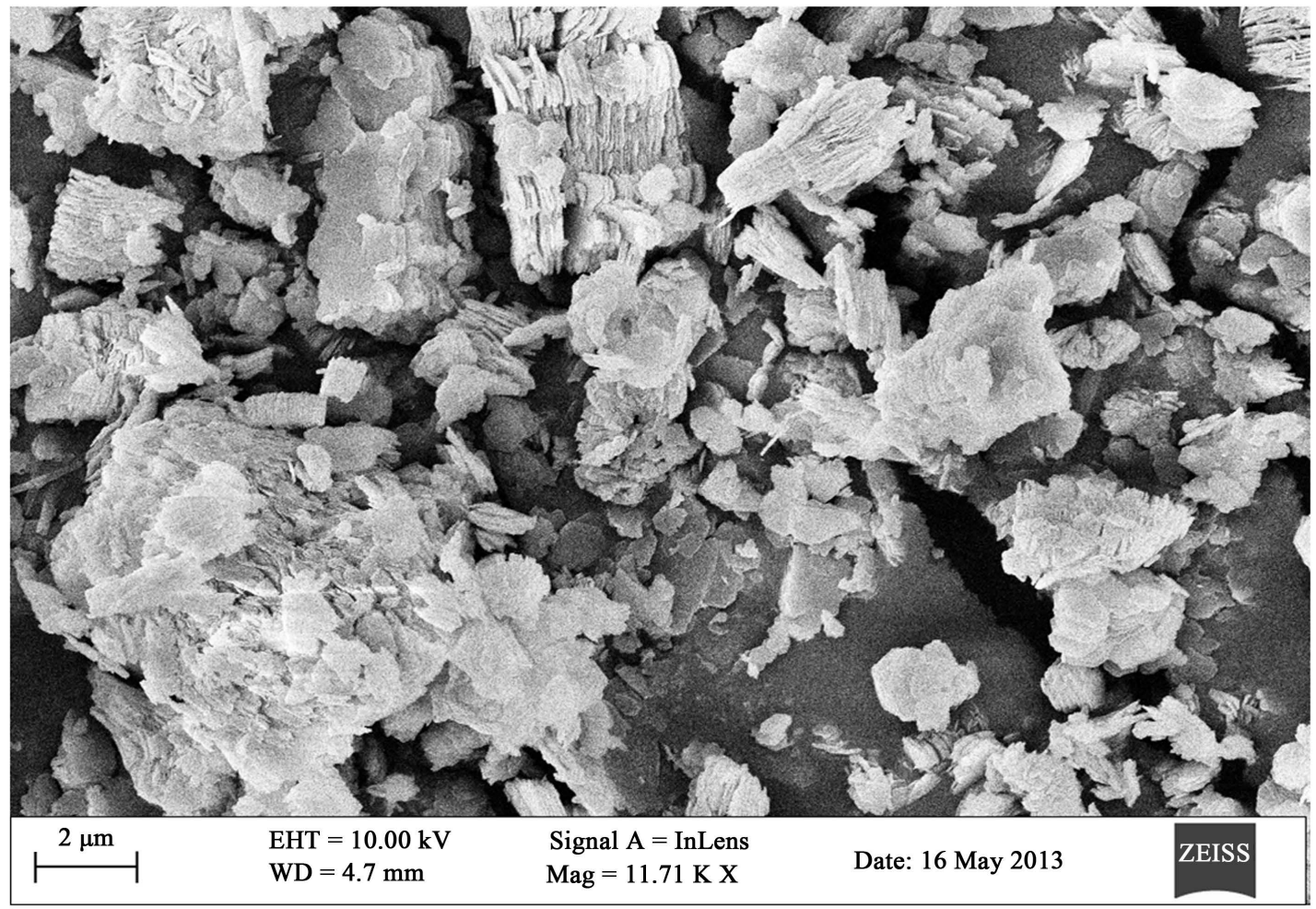

Figure 8 . Micrograph of sample with $15 \%$ grey cast iron. 


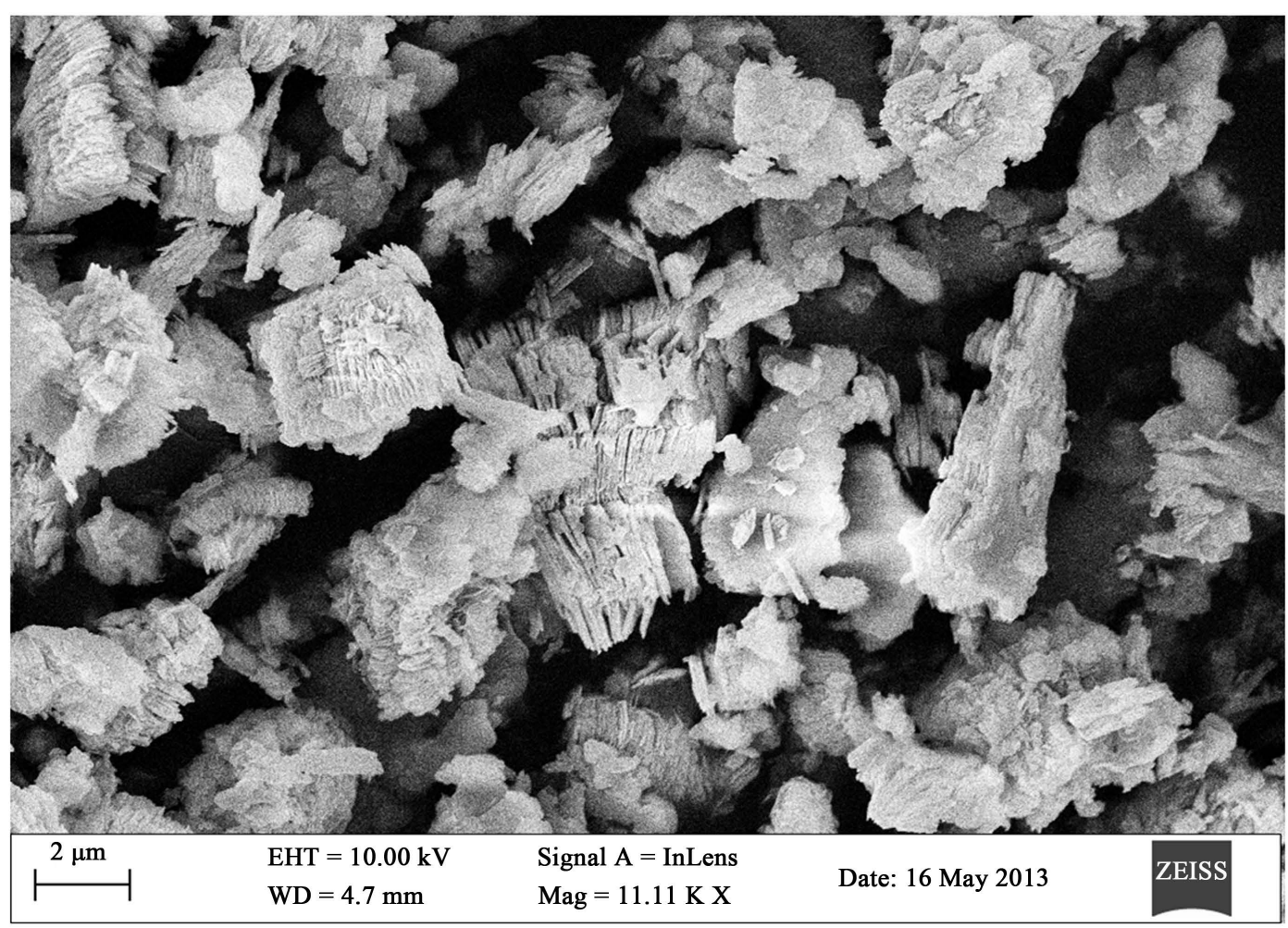

Figure 9. Micrograph of sample with $20 \%$ grey cast iron.

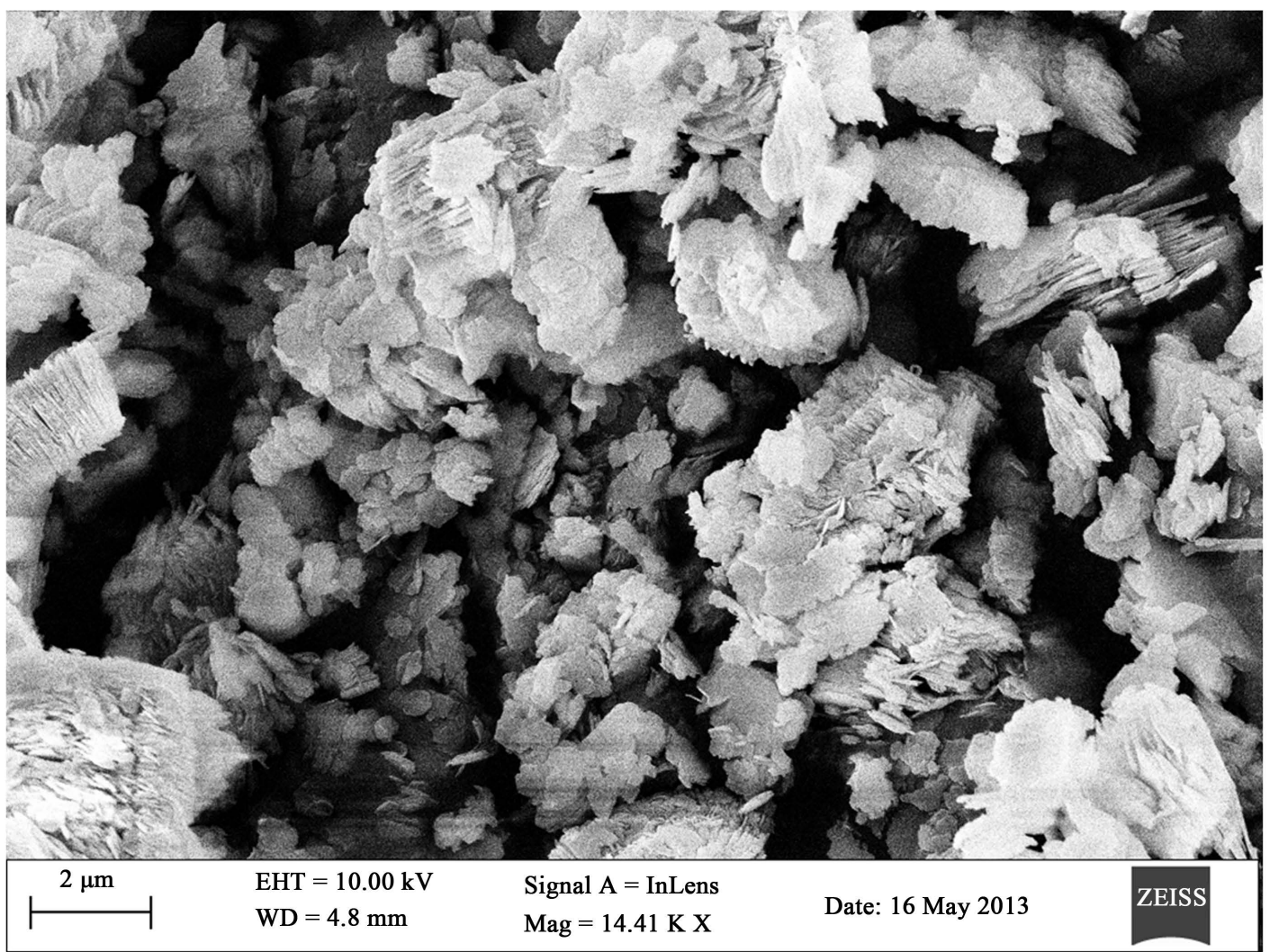

Figure 10. Micrograph of sample with 25\% grey cast iron. 


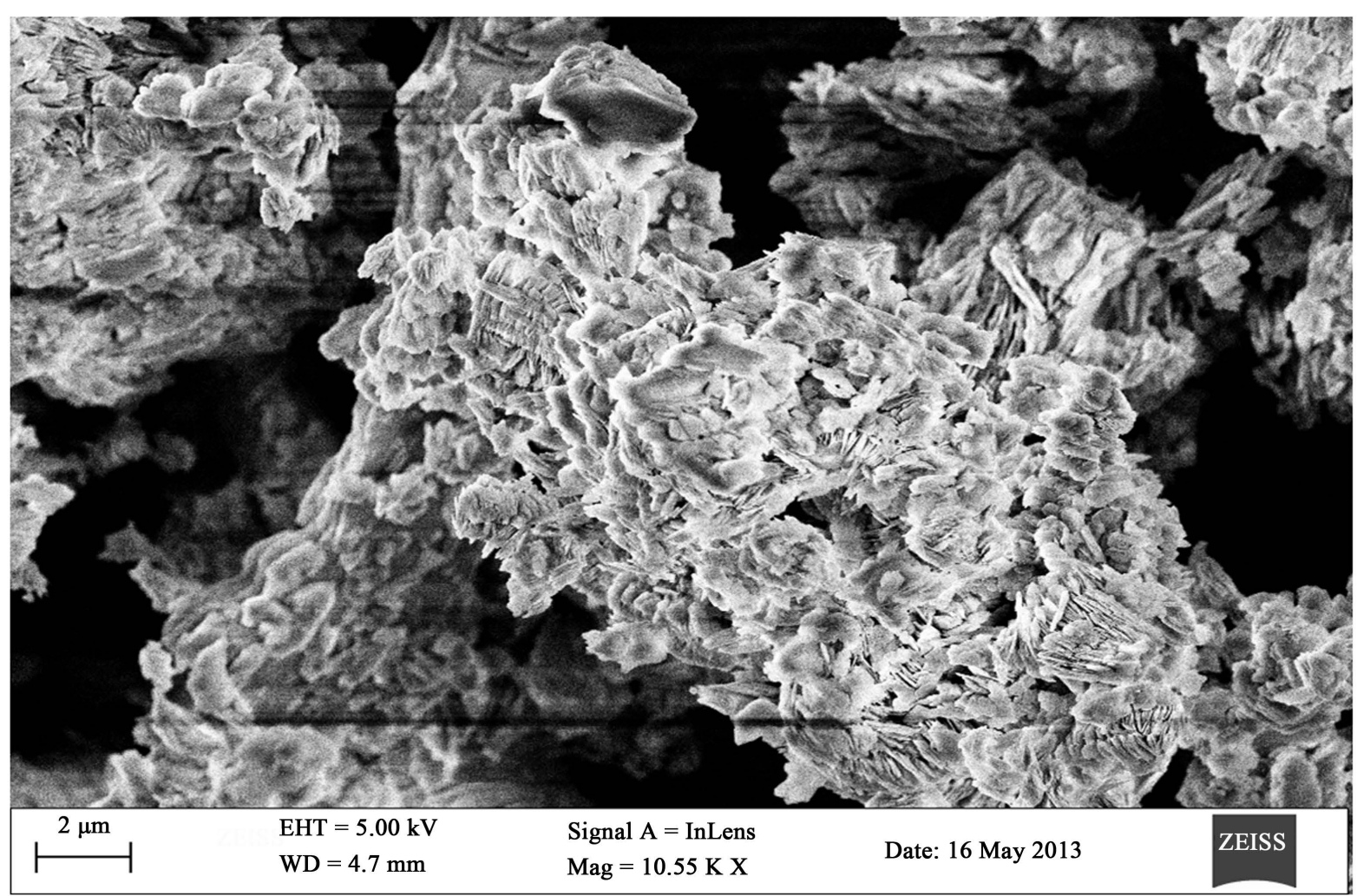

Figure 11. Micrograph of sample with 30\% grey cast iron.

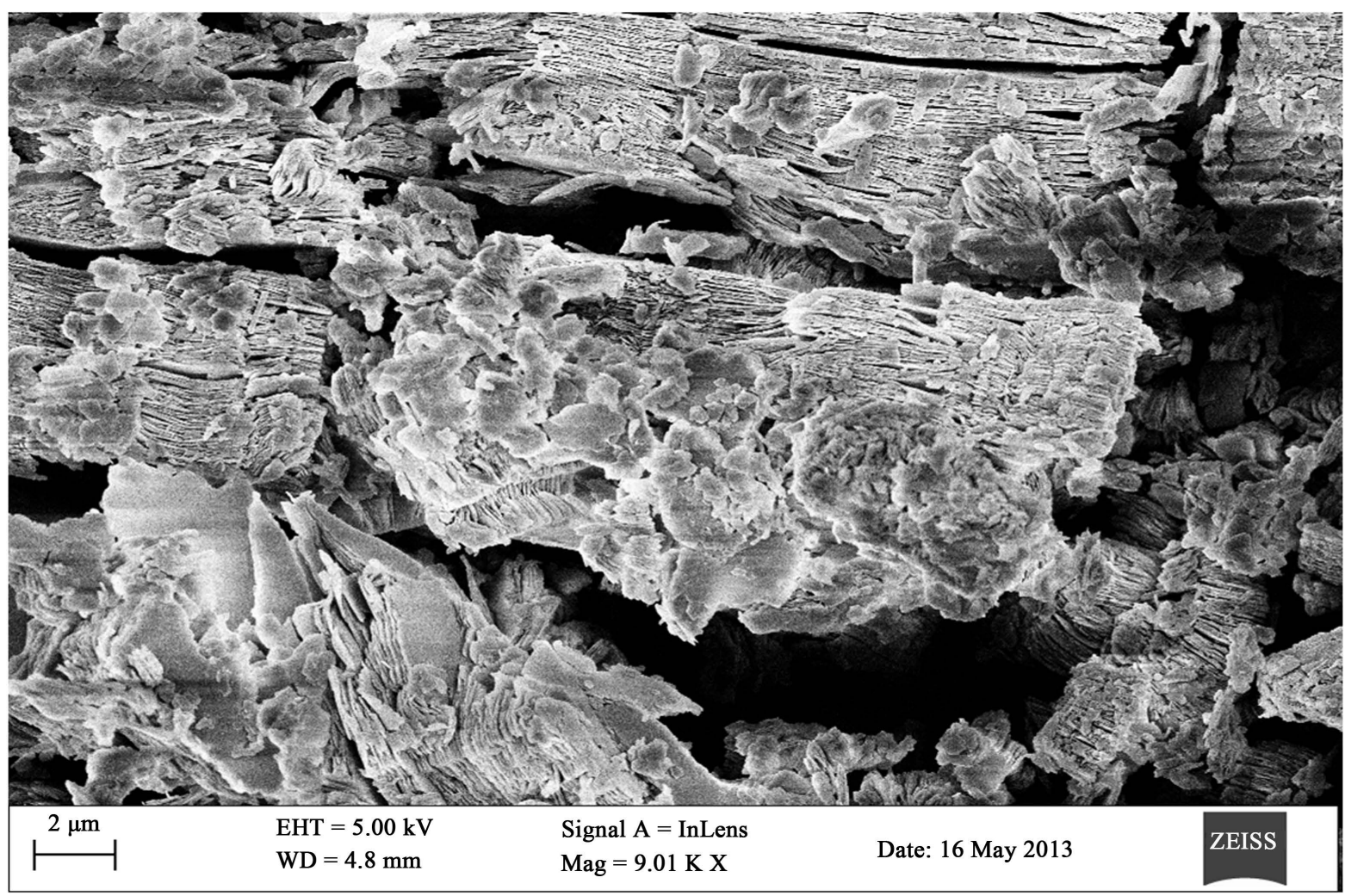

Figure 12. Micrograph of sample with 35\% grey cast iron. 


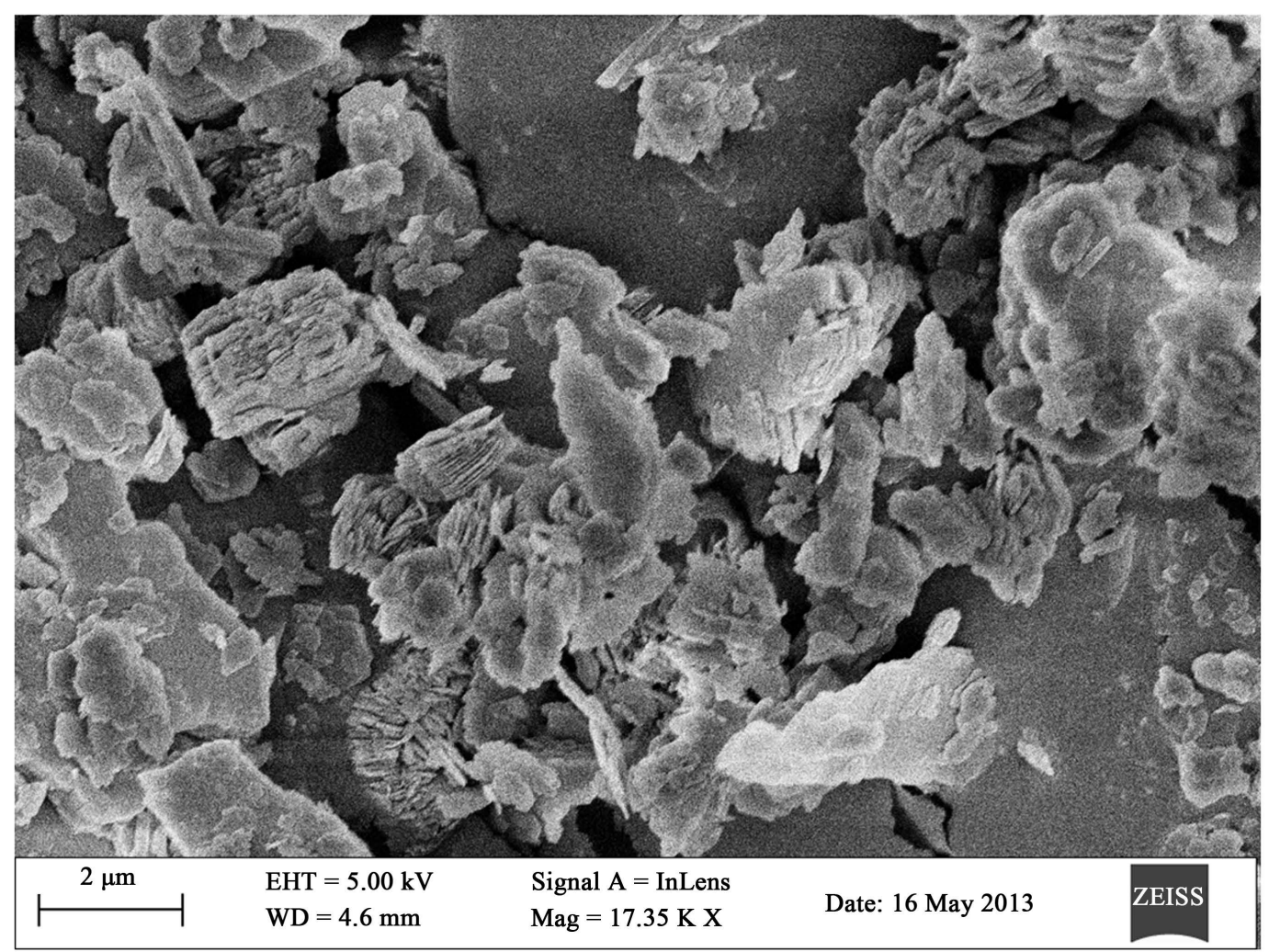

Figure 13. Micrograph of sample with $40 \%$ grey cast iron.

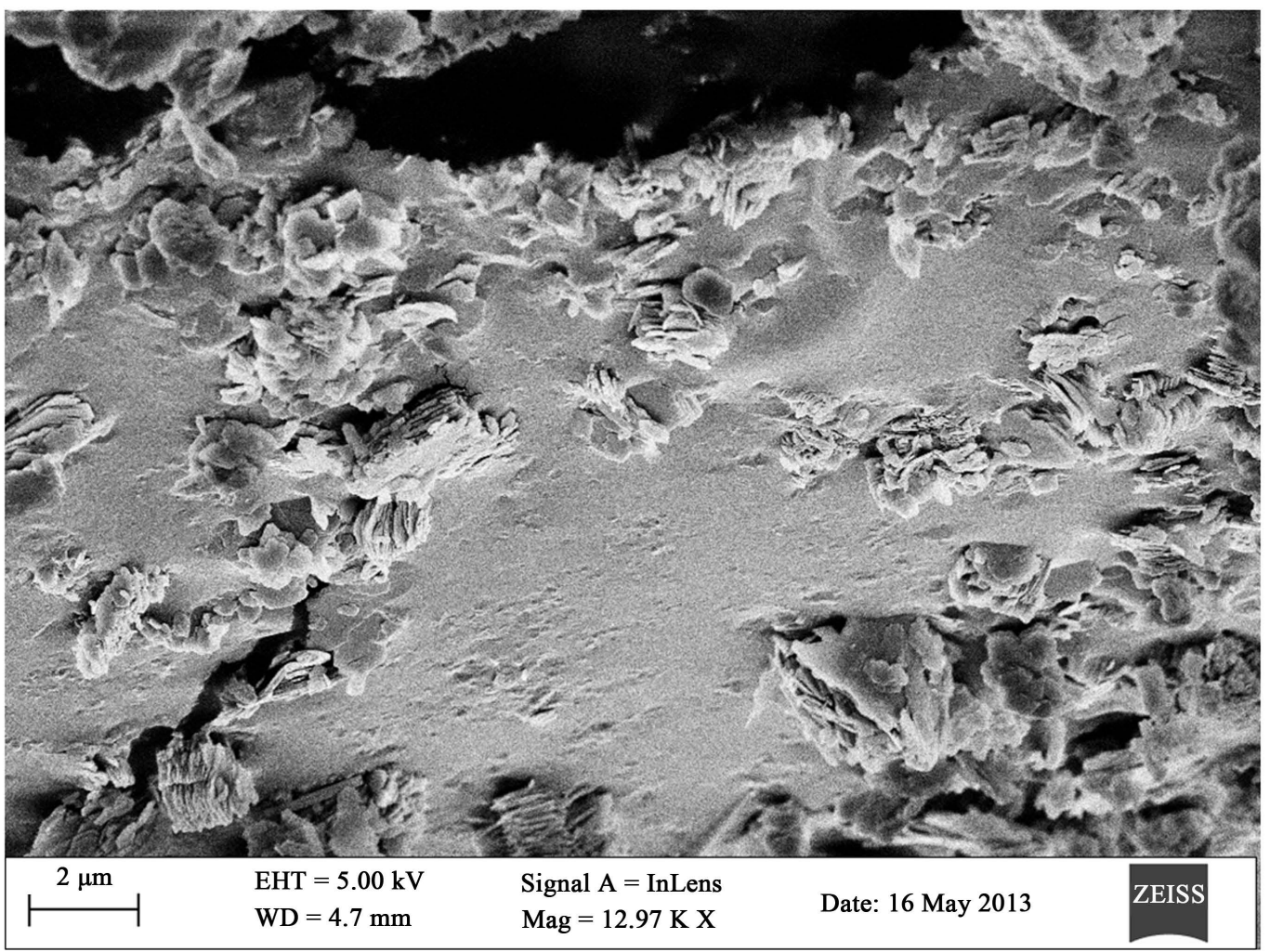

Figure 14. Micrograph of sample with $45 \%$ grey cast iron. 
was placed between the platens of the press and bearing faces of the test pieces which were placed centrally on the platen. Load was applied at a rate of $20 \mathrm{kN} /$ minute using hydraulic press. The maximum load was recorded as the crushing load. The crushing strength was calculated using the following formula.

$$
\text { C.C.S }=\frac{\operatorname{Load}(\mathrm{N})}{\operatorname{Area}\left(\mathrm{m}^{2}\right)}
$$

The hardness test of composites is based on the relative resistance of its surface to indentation by an indenter of specified dimension under a specified load. Hardness of the composites were determined, according to ASTM D2240 ISO 7619, by a direct reading durometer manufactured by franscisco Munoz Irles, C.B. (model: 5019 and Serial No: 01554). The durometer measures in shores. This test was carried out in the Nigerian Institute for Leather and Science Technology (NILEST), Samaru, Zaria.

The bulk densities of the developed samples were determined using the ratio of their weight to their volume. The volumes of the samples were determined by the products of their length, width and height. Then their masses were obtained using a digital balance. The densities were then calculated using Equation (5) below. [6]:

$$
\text { density }=\frac{\text { mass }}{\text { wolume }}
$$

The water absorption was determined as the percentage of water absorbed by the samples. After firing, the samples were weighed and their weight recorded. They are then soaked in water at room temperature for a period of 24 hours after which their weights are again taken. Equation (6) below is then used to obtain the percentage water absorbed.

$$
\% W \cdot A=\frac{W_{w}-W_{d}}{W_{d}}
$$

where;

$W_{d}$ : dry weight before soaking,

$W_{w}$ : wet weight after socking.

Apparent porosity was determined using three different weights. The weight of the sample after air drying was measured and recorded as dry weight $(D)$, the sample was then oven dried to a steady weight $(S)$. After this, the sample was then soaked in water for a period of $24 \mathrm{hrs}$. Then the new weight was measured and recorded as wet weight $(W)$. The Apparent porosity was then calculated using Equation (7) below

$$
P_{(a p p)}-\frac{W-D}{W-S} \times 100(\%)
$$

The tensile strength the test was also carried out using soil test compression machine Model 4839 S/No 1482. For the test, the specimen was placed diagonally between the platens of the machine. The maximum loads reached before failure by the samples were measured and the tensile strengths were calculated using equation below;

$$
U T S=\frac{\operatorname{Maximum} \operatorname{Load}(\mathrm{N})}{\operatorname{Area}\left(\mathrm{m}^{2}\right)}
$$

The compressive test was also carried out on soil test compression machine model $4839 \mathrm{~S} / \mathrm{No} 1482$. The test was similar to the cold crushing strength testing, but the samples were not soaked before testing. The maximum compressive loads reached by the samples before failure were measured and the compressive strengths were calculated using the equation below:

$$
U T S=\frac{\text { Maximum Compressive Load }(\mathrm{N})}{\operatorname{Area}\left(\mathrm{m}^{2}\right)}
$$

The X-ray diffraction patterns of composites were determined by X-ray analysis which was carried out to determine the various element and phases distribution in the samples. The test was carried out on a Philips X-ray diffractometer. Some X-ray diffractograms was taken using CoK $\alpha$ radiation at scan speed of $3 \mathrm{~m} / \mathrm{min}$.

Thermo gravimetric analysis studies of samples were carried in a nitrogen atmosphere on a thermal analyzer 
(Perkin Elmer) at a heating rate of $10^{\circ} \mathrm{C} / \mathrm{mm}$. The objective of thermal analysis is to study the effect of heating on the materials so that the stability of the materials at elevated temperature could be known for its applications in various fields. In this method a change in thermal stability was examined in terms of percentage weight loss as a function of temperature. At the same time DTA involves comparing the precise temperature difference between a sample and an inert reference material.

The particle sizes of the samples have been calculated employing the Scherres equation:

$$
D=\frac{K \lambda}{\beta \cos \theta}
$$

where $\theta$ is the angle between the incident and diffracted beams (degree), $\beta$ the full with half maximum (rad.), $D$ the particle size of the sample (nm) and $\lambda$ is the wave length of the $\mathrm{X}$-ray.

\section{Results and Discussion}

The results of the research work are presented in Figures 15-23.

\subsection{Physical Properties}

\subsubsection{Bulk Density and Porosity}

The results of the study of bulk density and apparent porosity of the developed composite material are shown in Figure 15 and Figure 16 respectively. From the results, it is seen that the bulk density of the developed material increased from 1.72 to $2.09 \mathrm{~g} / \mathrm{cm}^{3}$ (amounting to about 22\% increase) with increase in the percentage of the grey cast iron added. This increment is associated to the high density of the cast iron powder as compared to that of the clay. The variation in densities of the composite material is in agreement with the earlier work carried out by [7].

Figure 16 reveals that apparent porosity of the developed material was decreasing with increase in the percentage of cast iron added to the material. The apparent porosity decreases from $45.33 \%$ to $16.07 \%$. This can be associated with the role played by the melting of the cast iron powder into solids within the composite materials which reduces the number of pores present in the composite material.

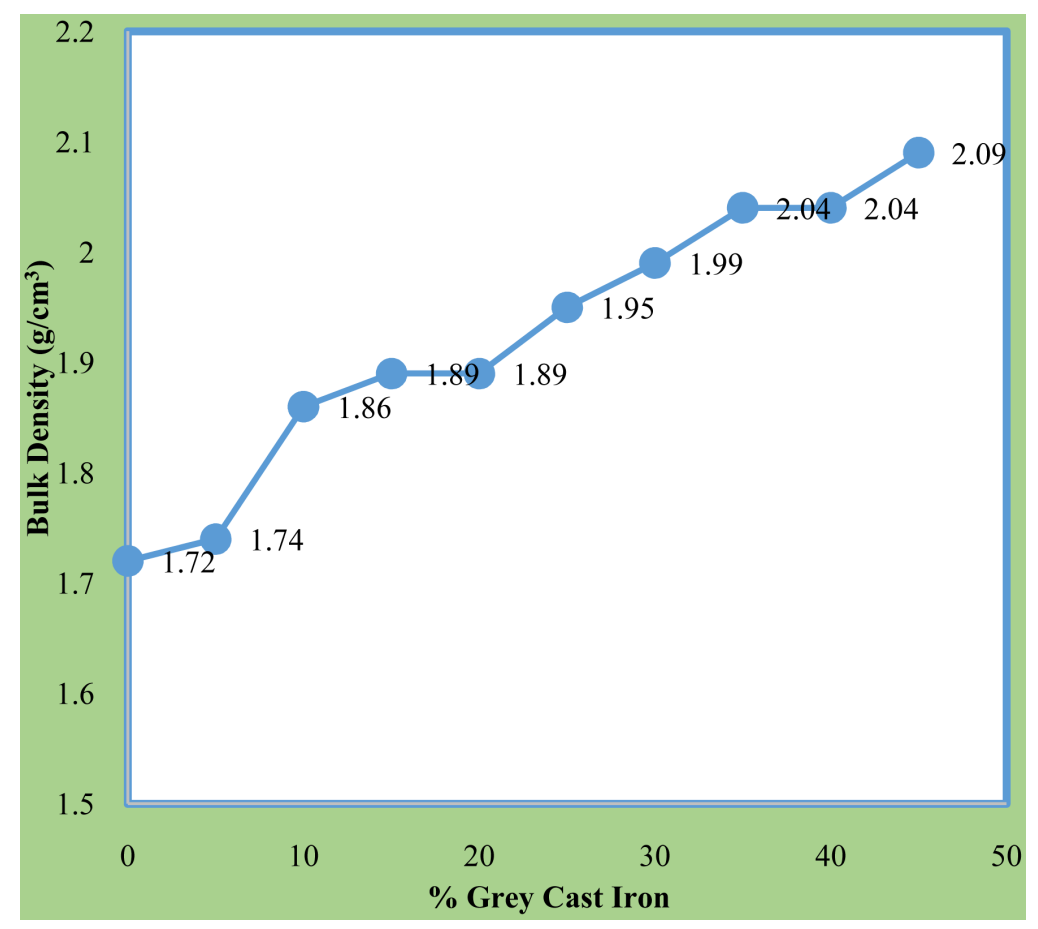

Figure 15. Variation of bulk density with GCI. 


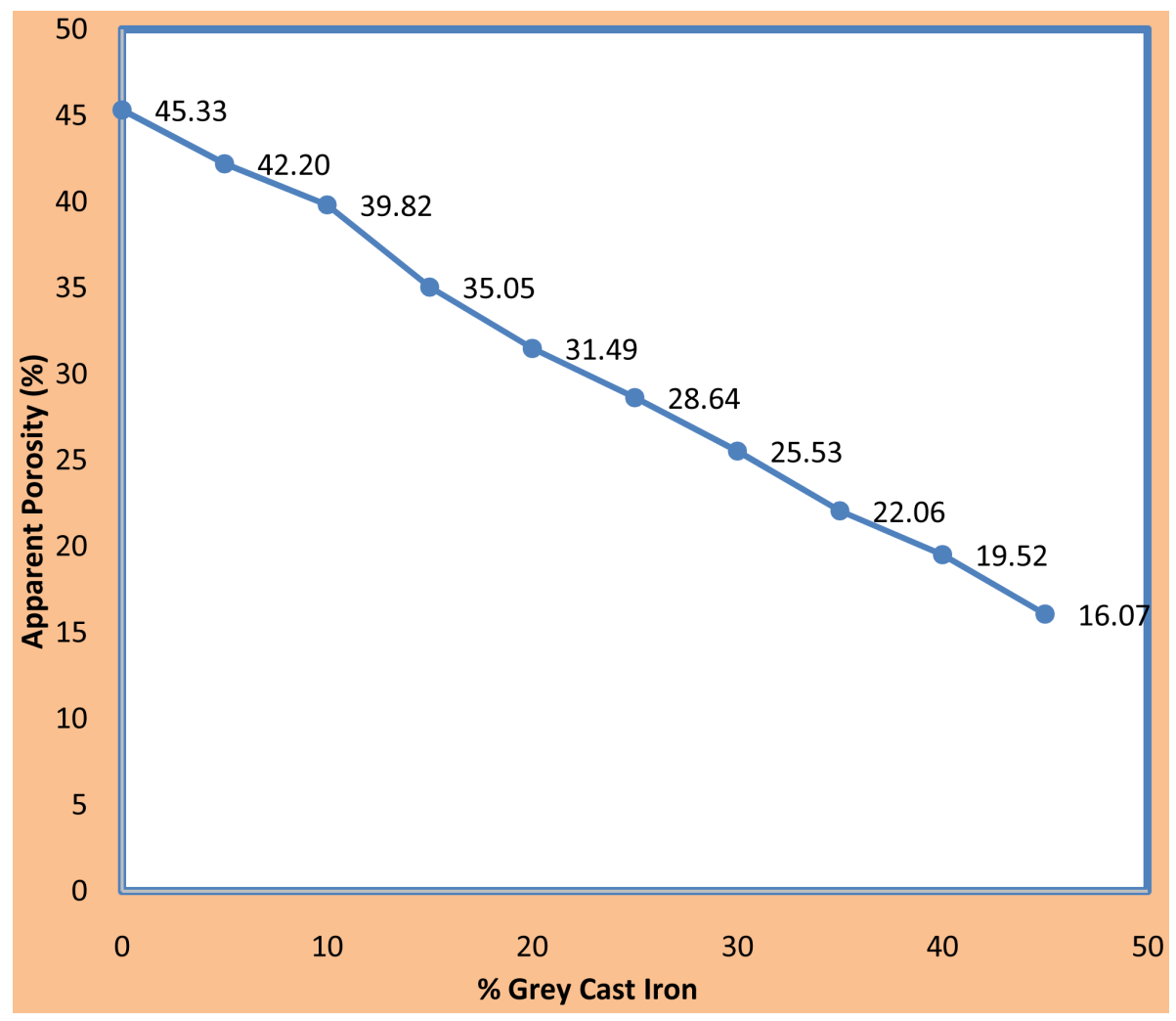

Figure 16. Variation of apparent porosity with \%GCI.

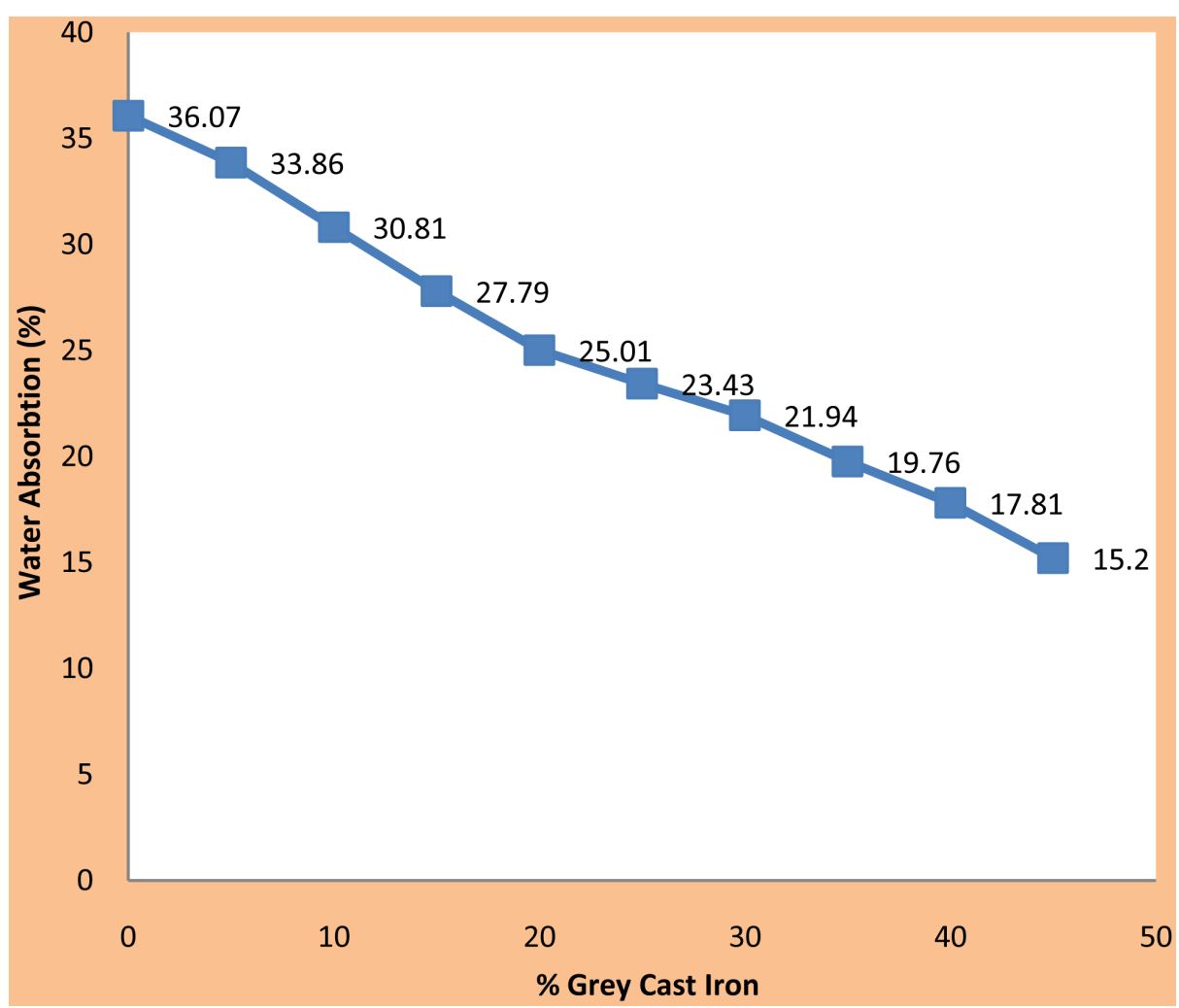

Figure 17. Variation of water absorption with \%GCI. 


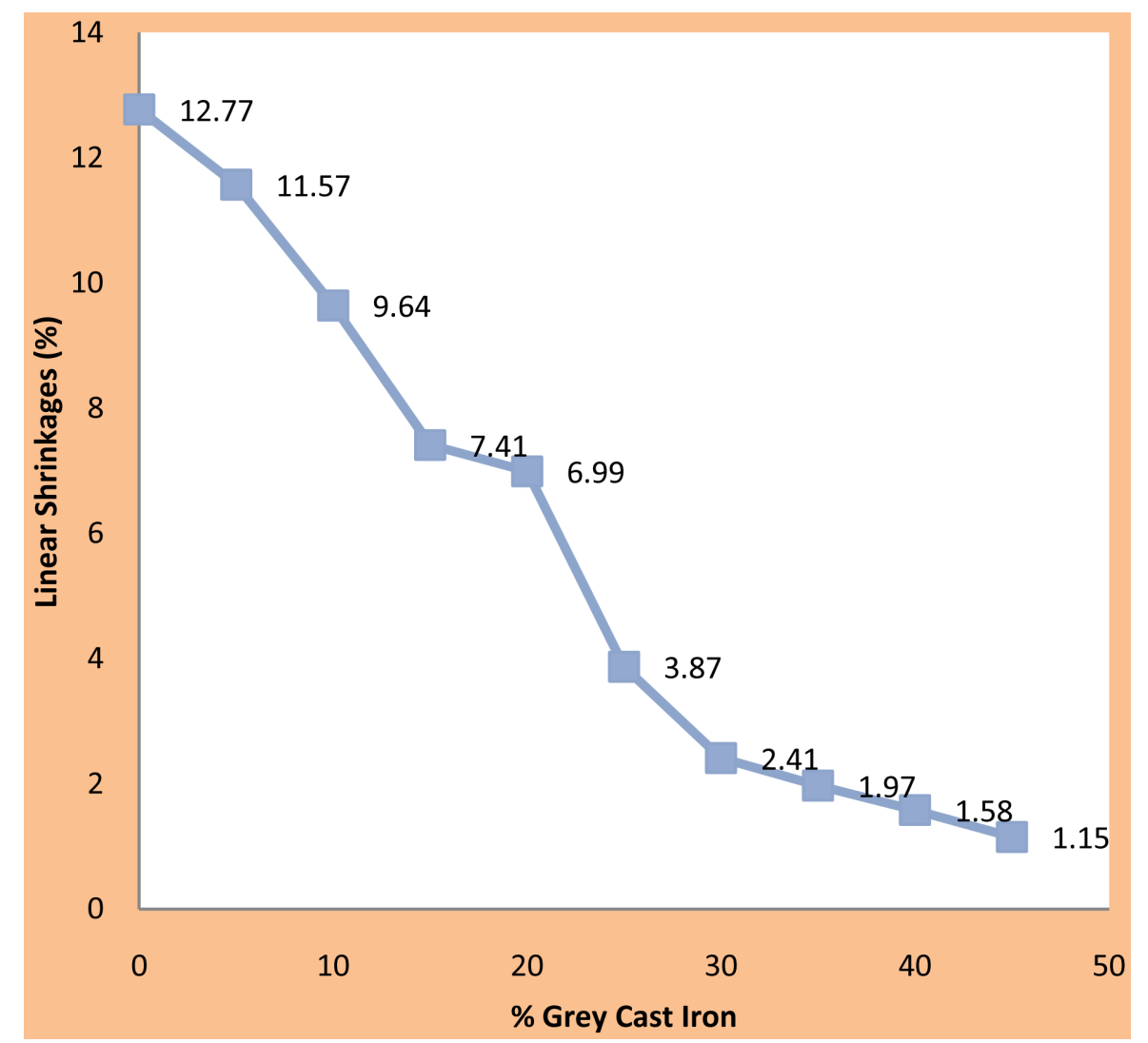

Figure 18. Variation of linear shrinkages with \%GCI.

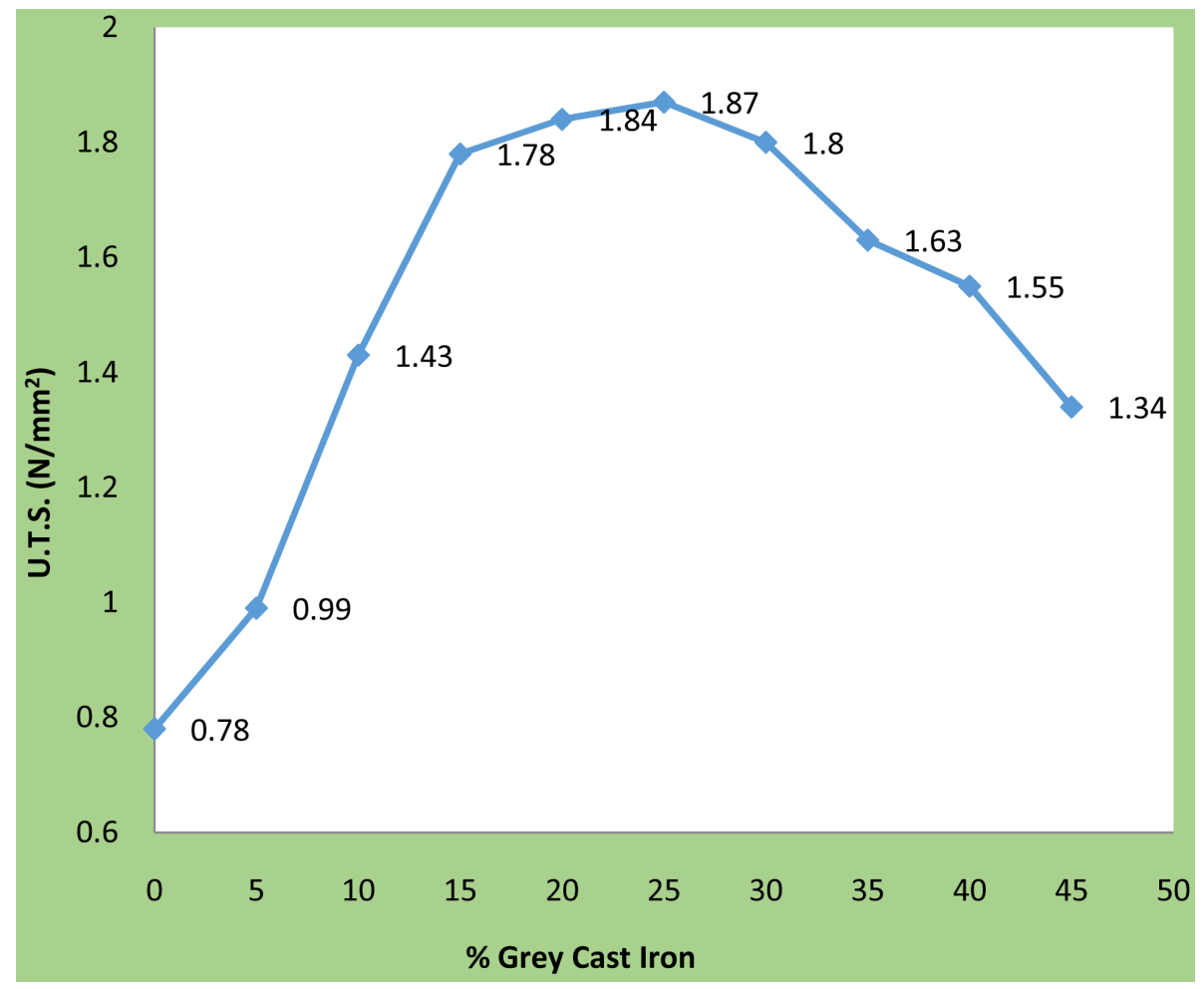

Figure 19. Variation of ultimate tensile strength with \%GCI. 


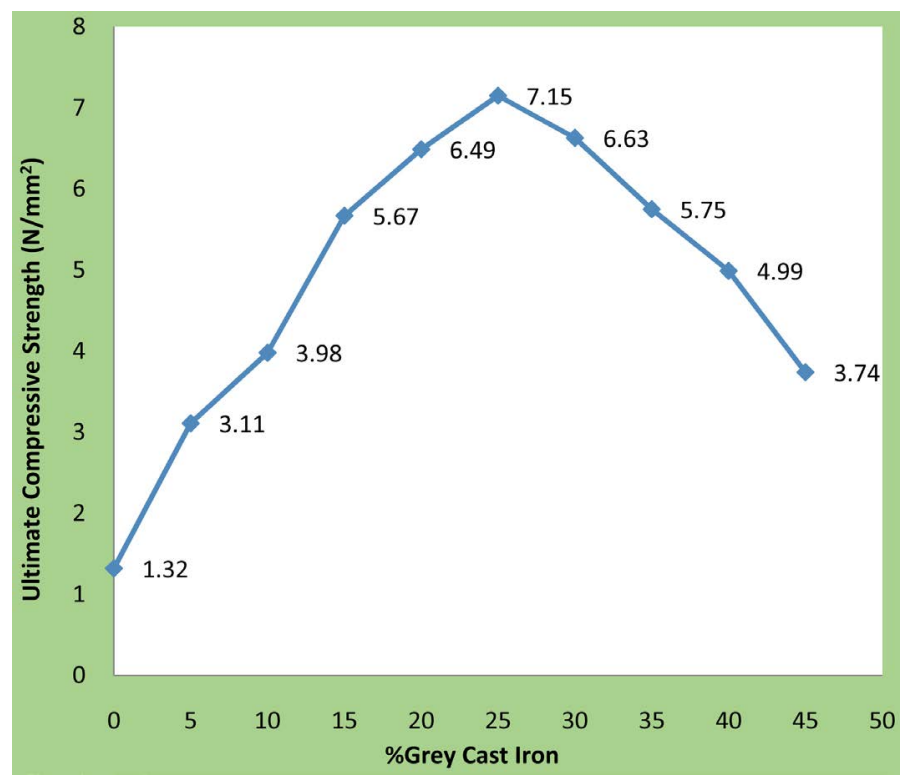

Figure 20. Variation of compressive strength with \%GCI.

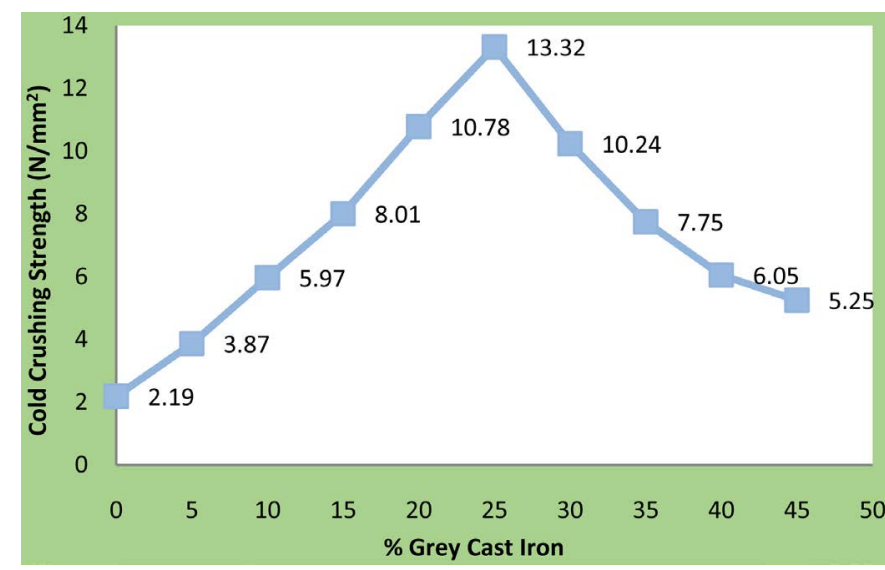

Figure 21. Variation of cold crushing strength with \%GCI.

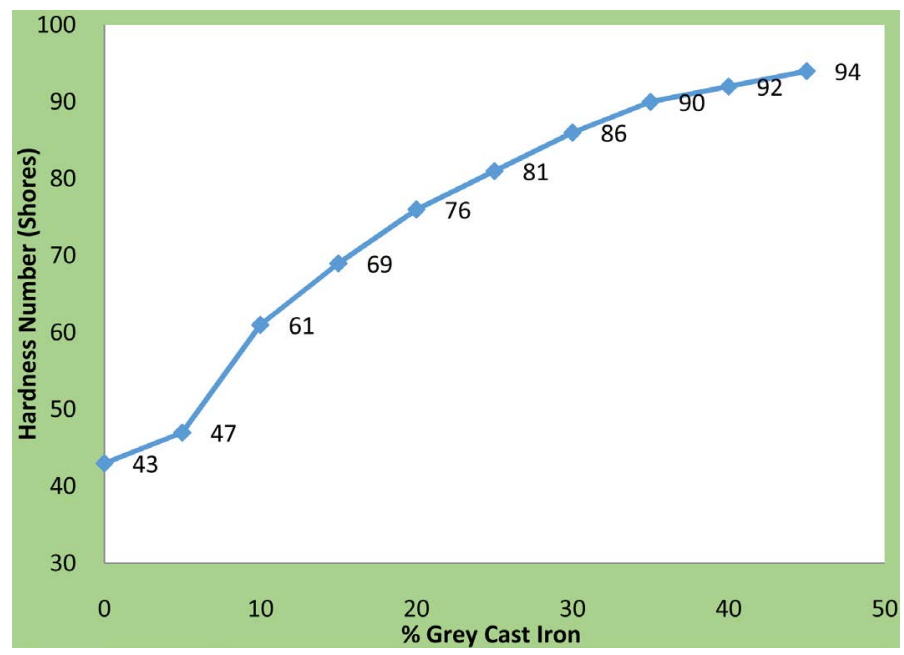

Figure 22. Variation of hardness number with \%GCI. 


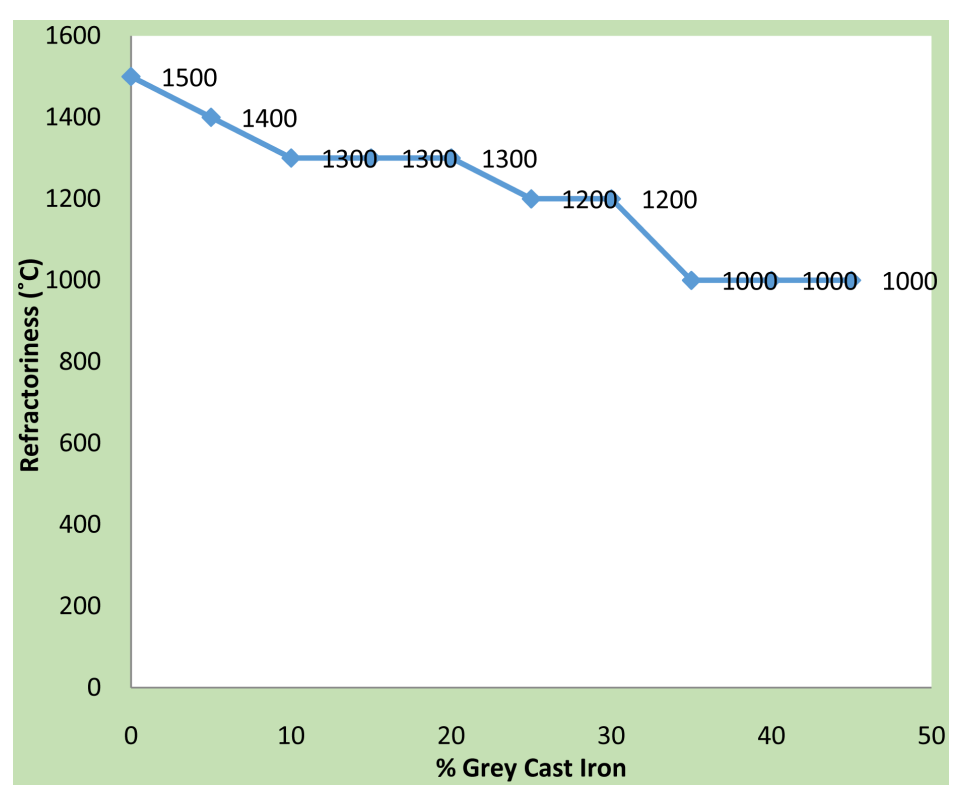

Figure 23. Variation of refractoriness with \%GCI.

\subsubsection{Water Absorption}

Water absorption values obtained for the developed composite materials are presented in Figure 17, this shows that the rate at which the developed composite materials absorb water decreased, from $36.07 \%$ to $16.94 \%$, with increase in percentage of grey cast iron added. As expected, the introduction of grey cast iron reinforcement into the clay matrix lowers the rate at which it absorbs water.

\subsubsection{Linear Shrinkages}

Figure 18 presents the results of linear shrinkage calculations for the developed composite materials the figure shows a general decrease in linear shrinkage with increase in the percentage of cast iron added. The linear shrinkages decreased from $12.77 \%$ to $1.55 \%$, amounting to about $81 \%$ improvement in linear shrinkage performance. It is worthy of note that the new lengths recorded do not take into account the outpour of excess cast iron melt, therefore negative values were avoided as they were recorded in the pilot study. The length then begins to increase with further addition of cast iron to the material. This can be explained by the principle of saturation of a mixture. The mixture of clay and cast iron reach saturation level which lead to the outpour of excess cast iron melt, thereby increasing the samples length. The amount of outpour increases with increase in the percentage of cast iron added to the composite material which accounts for increase in length of the composite materials after firing.

\subsubsection{Refractoriness}

Figure 23 shows that the refractoriness of the developed composite materials decrease with increase in the percentage of cast iron. Although the melting point of cast iron is high and the refractoriness of pure kaolin was also high, the resulting mixture of the two materials produces material with lower refractoriness. This can be associated to thermal instability resulting from the mixture of the two materials.

\subsection{Thermal Properties}

The DTA/TGA analysis revealed that initial weight loss ( $10 \%)$ observed between $500^{\circ} \mathrm{C}$ and $600^{\circ} \mathrm{C}$ is attributable to the vaporization of the water from the samples, while degradation of the composites started at higher temperature, precisely after $550^{\circ} \mathrm{C}$ above which thermal stability of samples gradually decreased and eventual degradation of the samples ensued.

DTA curve shows that the temperature of maximal decomposition/ destruction was $520^{\circ} \mathrm{C}-600^{\circ} \mathrm{C}$. The presence of endothermic effects in samples are results of two processes-dehydrogenation and evaporation of some non-cellulosic materials. This conclusion was confirmed by the decreased mass of the sample. The DTA curve 
also confirmed these results.

The endothermic effects observed in the temperature range indicated above were probably as a result of the bonds formed in the clay backbone. Finally, it is worthy of note that the thermal analysis curves reveal that samples are stable until around $700^{\circ} \mathrm{C}$. This is in agreement with values of some other clay materials reported in literature.

All the composites showed a small $(10 \%)$ weight loss around $500^{\circ} \mathrm{C}$, which can be attributed to the evaporation of water. The weight loss rate gradually increased above $600^{\circ} \mathrm{C}$ and distinct weight loss appearing between $500^{\circ} \mathrm{C}$ to $600^{\circ} \mathrm{C}$. The results showed that addition of grey iron particles to kankara does not alter the thermal decomposition process since at temperatures greater than $900^{\circ} \mathrm{C}$ the samples retained $80 \%$ wt. From Table 1 .

$\mathrm{T}_{10 \%}{ }^{\circ} \mathrm{C}=$ temperature at which $10 \%$ of the original weight is lost

$\mathrm{T}_{90 \%}{ }^{\circ} \mathrm{C}=$ temperature at which $90 \%$ of the original weight is lost

$\mathrm{T}_{\max }{ }^{\circ} \mathrm{C}=$ temperature at maximum decomposition

\section{Conclusions}

From the above results and discussion, the following conclusions are made:

1. Characterization study of the Kankara clay (kaolin) and grey iron powder was successfully conducted.

2. The production of ceramic composite refractory using powder metallurgy technique, blending by varying the percentage of grey iron powder from 5 - $45 \mathrm{wt} \%$ in the Kankara clay (kaolin) is attainable, with good refractory properties.

3. The mechanical properties test results of hardness value, cold crushing strength, ultimate tensile strength and ultimate compressive strength on the developed composite refractory shows an increase in the mechanical properties with increasing grey cast iron content up until attaining a weight content of $25 \%$. After this wt $\%$, it is observed that there is a decrease in these mechanical properties.

4. The physical properties test result of bulk density, porosity, linear shrinkage and water absorption on developed composite refractory shows an increase in bulk density with increasing grey cast iron content. However porosity, linear shrinkage and absorption decrease with increasing grey cast iron content.

5. Micro structural analysis (i.e. scanning electron microscopy (SEM) X-ray diffraction (X-RD) and X-ray fluorescence (X-RF) have shown an even spread of the elements of the composite.

6. The utilization of kankara clay and gray cast Iron for the production of composite refractory has been successfully carried out using $25 \mathrm{wt} \%$ grey cast iron developed into composite refractory.

7. The developed composite is observed to be plastic up to $25 \mathrm{wgt} \%$ grey cast iron content.

\section{References}

[1] Hsieh, C.L. and Tuan, W.H. (2005) Investigated Elastic Properties of Ceramic-Metal Particulate Composites. Materials Science and Engineering: A, 393, 133-139. http://dx.doi.org/10.1016/j.msea.2004.10.009

[2] Ewule, J.O. (1988) Development of Model Gas Kiln for Ceramic Production from Local Resources. M.A Thesis, Ahmadu Bello University, Zaria.

[3] Schussler, A. and Zum Gahr, K.H. (1993) Ceramic-Metal Composite Surface Layers by Laser Processing. International Journal of Materials and Product Technology, 8, 213-219.

[4] Sullayman, U.K.A. (2005) Utilization of Local Raw Materials for the Production of Dense Aluminosilicate Refractory Bricks for Blast Furnaces Using Semi Dry Pressing Technique, Ph.D., Dissertation, Department of Industrial Design, A.B.U, Zaria.

[5] Sullayma, U.A.A. (2011) LAP LAMBERT Academic Publishing, GmbH \& Co. KG Heinrich Bocking Str. 6-8, Saarbrucken, Germany.

[6] Clyne, T.W. (2000) Comprehensive Composite Material, Vol. 3, Metal Matrix Composites (ser, Eds).

[7] Ramachandra, M. and Radhakrishna, K. (2006) Sliding Wear, Slurring Erosive Wear and Corrosive Wear of Aluminium/SiC Composite. Journal of Materials Science, Poland, 24, 334-349. 